\title{
A Framework for Understanding the Uncertainty Across Energy Model Stages and Methodologies
}

\author{
Patrick Alan Pease ${ }^{1}$, Nada Tarkhan ${ }^{1}$, Chan Mi Hwang ${ }^{1}$ \\ ${ }^{1}$ Arup, Boston, USA
}

\begin{abstract}
This paper aims to investigate the methodologies employed in early stage modelling and to capture the deviations from final Leadership in Energy and Environmental Design (LEED) models. The research has focused on providing a framework to better understand how energy model results will change as the project, and model progresses. The goal is to ultimately gain insight into the sources of these deviations across building energy end uses and to learn from correlations between assumptions made and end use results. The data set was generated from projects that have achieved LEED certification as the final model. The early stage models were created based on a standardized methodology formed as part of this research.

The novelty of this research lies in understanding the sources of discrepancy in the models and proposing methods of enhancing accuracy throughout the process while building more robust, repeatable and shareable modelling approaches.
\end{abstract}

\section{Introduction}

Energy Models are typically built throughout the design process to estimate the building's annual energy usage. Schematic design-phase energy models are typically used by project teams to track energy code performance and understand building energy use. However, at early stages in design, many assumptions need to be made around zoning, building assemblies and system performance that all impact the final energy use result. While it is understood that actual measured performance differs from the modelled performance (Ahmad and Culp, 2006), few studies have focused on the deviations that exist between early stage energy models and final submitted LEED models that are detailed to reflect the final project performance.

This study acknowledges that the intentions of early stage models and LEED compliance models differ. Early stage models are often used on a comparative basis, to assess the impact of different ECMs (Energy Conservation Measures) so the emphasis on accuracy is not as great as that of detailed design models. Final energy models on the other hand, are intended to provide as close an estimate as possible to actual performance. Later stage models are also typically very time-intensive and demand higher processing power to run. In addition to this, these models also require that certain design information be made available such as system parameters and controls, and actual building occupancy. Studies on energy modelling workflows have shown that computational obstacles may be overcome by supercomputers, cloud computing, or metamodeling (Østergård, Jensen, and Maagaard, 2018). That is why it becomes imperative to build frameworks to best utilize the time given to build models in the various stages of the design.

The benefits of using energy modelling to inform design is also a topic that has been widely discussed. There has been accompanying literature that looks at improving accuracy and comparing different simulation engines as well as the impact of different modeller decisions (Berkeley, Haves and Kolderup, 2014). Discrepancies in modelling programs and techniques may lead users to lack confidence in building simulation methods and the results (Zhu, Hong, Yan, and Wang, 2013). It is for this reason that the simulation engine and software version were standardized in this study to eliminate the influence of modelling programs on the results. In addition to this, we investigate the impact of specific modelling techniques that also influence the results obtained. For instance, the translation of architectural massing models involves multiple manual steps and is therefore resource intensive (De Wilde, 1999). Some researchers have investigated the use of auto-zoning algorithms that use thermal zone discretization algorithms and see how they compare to guidance from ASHRAE 90.1 Energy Standard for Buildings Except Low-Rise Residential Buildings (Dogan and Reinhart, 2017).

This body of work looks at overall standard deviations across aggregate energy use and takes a closer look at the energy end uses to see if there are trends that can be identified. Throughout this process, more confidence is built on how different end uses evolve and change from project inception to finalization so as to clearly communicate this to clients and stake holders in the beginning of design. The value and insight provided can be used to provide grounding for more detailed system design as well such as HVAC equipment sizing.

In addition to this, the framework developed for early stage models will be tested and improved upon. This would reduce the time associated with identifying different modelling approaches on different projects and will enhance the robustness of the energy modelling practice. In the process of understanding uncertainties, the design exploration space is also navigated better (Nikolaidou and Christina, 2017). Key decisions on the selection of various ECMs are made with more reliable predictions of energy savings impact.

The paper uses standard modelling methodologies that are employed in the author's firm. The discussions and conclusion section provide additional insight into how 
frameworks and methodologies can be improved upon. The methodology highlights the selection criteria of the models as well as the step-by-step approach to creating these models.

\section{Method}

\section{Model Collection}

The first task undertaken in the study was to collect project information on completed and certified LEED buildings across the Americas region. LEED certified projects were chosen for the research as each model went through the U.S. Green Building Council (USGBC) review process. This was done via internal sustainability and energy modelling networks. An online form and SharePoint was used to gather classification information on each model along with the required results and model files. In total 19 models for projects ranging from laboratories to auditoriums and data centres were collected. To reduce variability in the results, projects done in Integrated Environmental Solution: Virtual Environment (IES:VE) were selected for the data set of final energy models. By doing this, the simulation software would be the standardized across both the final and early stage models.

The energy end use results of these final models were tabulated based on the LEED convention. Uncommon end uses such as Refrigeration Equipment and Industrial Process were omitted as the data set did not include enough examples of each. Table 1 shows the end uses included in the study.

Table 1: LEED convention energy end uses.

\begin{tabular}{|c|}
\hline Energy End Use \\
\hline Interior Lighting \\
\hline Exterior Lighting \\
\hline Space Heating \\
\hline Space Cooling \\
\hline Pumps \\
\hline Heat Rejection \\
\hline Fans Interior \\
\hline Service Water Heating \\
\hline Plug Load \\
\hline Elevators \& Escalators \\
\hline
\end{tabular}

\section{Early Stage Modelling Methodology}

The early stage model represents a simplified version of the final design. A set of rules were developed for guidance on modifying final geometry, envelop properties, internal gains, ventilation rate and system modelling for the early stage models. First, general geometry, like external shape and number of floor kept equal. The existing surroundings, such as adjacencies and existing parts of the building are kept the same as the final model. Individual zones are combined into fewer zones so that inputting parameter and simulating time can minimized. Two main zones exist, perimeter and core zone. Number of perimeter zone is based on external building shape. Due to solar orientation, each perimeter zone may experience peak heat gain different time of the day. Since final model zoning strategy is combining same oriented room into one zone, so a single variable air box (VAV) can control airflow rate into each room with experiencing thermal comfort. With regards to zoning, The American Society of Heating, Refrigerating and AirConditioning Engineer (ASHRAE) guidance is used and approximately $4.5 \mathrm{~m}$ perimeter zone, from external to internal, is assigned to all orientation. Detailed design considerations like local shading elements shall be removed from the final model to represent early stage model.

Secondly, all thermal envelope properties are aligned with final design rather than using code minimum per ASHRAE 90.1-table 5.5 Building Envelope Requirements. Since the early stage model is a comparison between the final model, not a code compliance baseline model, this method gives a more accurate compassion between the two models. This also reduces a large source of known error from the results. In the case of multiple and complex construction, rationalization has been applied to match overall $u$-value thermal performance. The glazing area percentage per orientation was assigned as per table 1.4 under LEED credit EA2 - Compass Direction. With the exception of heavily-weighted Southern glazing in some models, all other early stage model glazing percentages are based on overall area. Internal partitions are assigned as IES defaults and internal holes, internal windows and other internal features are removed from the simplified models.

Concerning internal gains, such as lighting, equipment, and people loads, a reassignment was carried out using ASHRAE space by space grouping as per the submitted LEED EAp1 Table 1.4 to match the final model area. However, due to simplifying zones, simplied space area approximately matches the final model area with a discrepency of $\pm 10 \%$. Unconditioned and unoccupied space, such as toilets, voids, stairs, IT rooms, and electrical rooms are omitted in the early stage model. However, a full floor plantroom and other process loads, such as data centers and full kitchens are kept and assigned as "elec/mech" spaces to capture the representative internal gains equal to the final model. The number of elevators in the early stage model was kept the same and assigned per peak energy demand. Equipment and occupancy gains as well as operating and occupied schedules are inherited from ASHRAE/IES:VE defaults. Internal lighting power density (LPD) has a large impact on the total internal gains in a space, therefore, the final design LPDs were captured in the early stage model. The external lighting power is based on ASHRAE 90.1 - 2007 with addendum 1 and 2010 lighting zone 3 baseline site allowance. Fourth, the minimum ventilation rate and occupancy density per person requirement is based on ASHRAE 62.1 Ventilation for acceptable Indor Air Quality. The number of occupants in the final model will not exactly match the simplified model since the simplied version is using code approximation and the final is using exact occupancy, coordinated with the architect. The infiltration rate per square foot of façade area was matched from the final design. Since the exterior façade 
area in the two models is the same, total infiltration will be consistent.

Lastly, the service hot water usage and the prototype HVAC system are modelled. The service hot water is matched to the final model, but where there is lack of information from the final model report, 0.25 liter per hour per person is applied to all occupied spaces, and its operating scheduled is linked to the space occupancy. Design heating and cooling setpoints are set based on ASHRAE 55 Thermal Environmental Conditions for Human Occupancy guidance. Indoor winter temperature is set to $21^{\circ} \mathrm{C}$ at occupied hours and $15^{\circ} \mathrm{C}$ at unoccupied hours. Summer temperature is set to $23^{\circ} \mathrm{C}$ at occupied hours and $26^{\circ} \mathrm{C}$ at unoccupied hours.

With regards to HVAC systems, the early stage model follows IES:VE default prototypes based on the final model system type. The spaces are grouped into minimal systems to simplify the model and decrease simulation time. Heat or enthalpy recovery effectiveness applied to the early stage models matches the final design effectiveness. The Airside economizer, minimum VAV turndown, heating hot water and chilled water pump configuration and associated power, are set per ASHRAE 90.1. Figure 1, captures these assumptions and summarizes the discussed methodology.

Table 2: LEED certified projects used for study.

\begin{tabular}{|c|c|c|c|c|c|c|}
\hline Project ID & Building Type & $\begin{array}{c}\text { Climate } \\
\text { Zone }\end{array}$ & $\begin{array}{c}\text { Gross Area } \\
\mathbf{m}^{\mathbf{2}}\end{array}$ & Cooling Source & Heating Source & $\begin{array}{c}\text { Energy Code } \\
\text { [ASHRAE] }\end{array}$ \\
\hline Lab_5A_01 & Laboratory & 5A & 22,770 & Electric & Natural Gas & $90.1-2007$ \\
\hline Lab_5A_02 & Laboratory & 5A & 14,800 & Electric & Natural Gas & $90.1-2007$ \\
\hline Lab_5A_03 & Laboratory & 5A & 5,200 & Electric & Natural Gas & $90.1-2007$ \\
\hline Assembly_5A_01 & Assembly & 5A & 1,600 & Purchased CHW & Purchased HHW & $90.1-2007$ \\
\hline Dining_5A_01 & Dining & 3C & 1,900 & Electric & Natural Gas & $90.1-2007$ \\
\hline Office_3A_01 & Office & 3A & 29,300 & Electric & Electric & $90.1-2007$ \\
\hline Office_3A_02 & Office & 3A & 13,700 & Electric & Electric & $90.1-2007$ \\
\hline Office_3C_01 & Office & 3C & 19,700 & Purchased CHW & Natural Gas & $90.1-2007$ \\
\hline Office_3C_02 & Office & 3C & 27,000 & Electric & Electric & $90.1-2007$ \\
\hline Gym_3C_01 & Gym & 3C & 7,6000 & Purchased CHW & Natural Gas & $90.1-2010$ \\
\hline Education_3C_01 & Education & 3C & 5,100 & Electric & Natural Gas & $90.1-2010$ \\
\hline
\end{tabular}

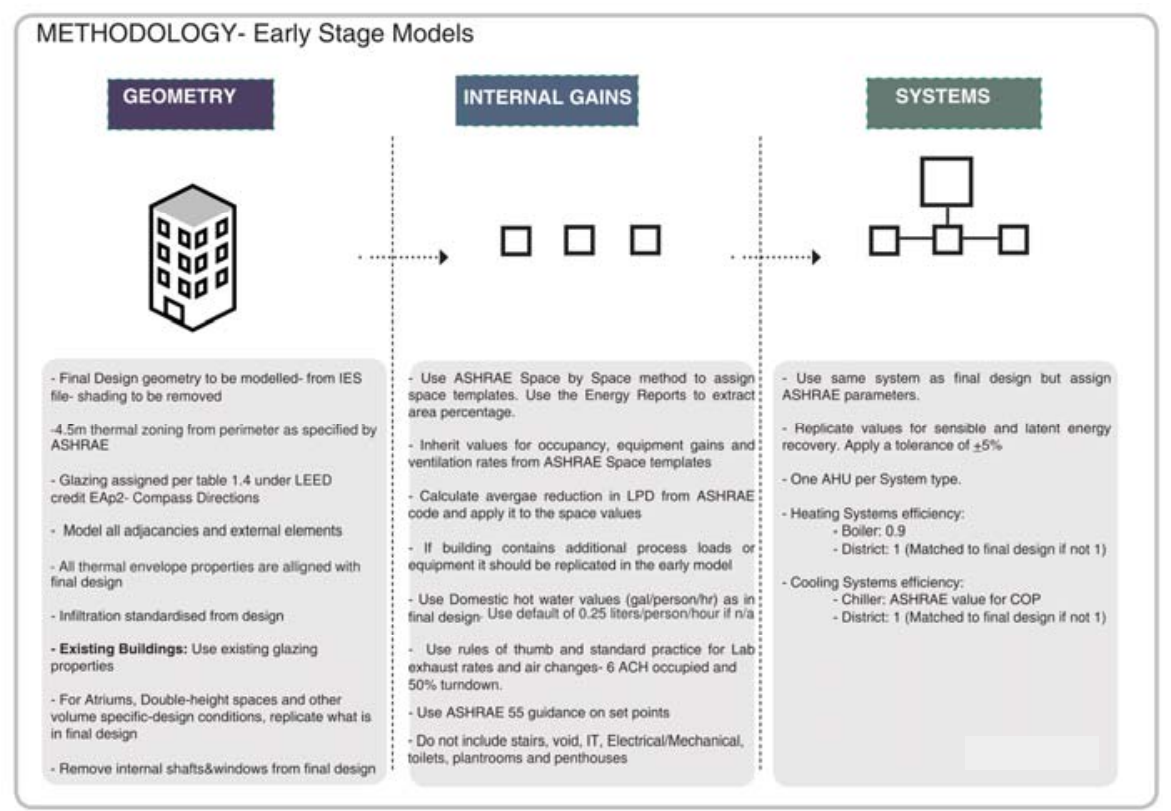

Figure 1: Early stage model methodology.

Laboratory spaces will not follow ASHRAE 62.1 ventilation requirements but will rely on rules of thumb and ASHRAE 170 Ventilation of Health Care Facilities. An air change of 6 is applied during occupied hours and an air change of 3 during unoccupied hours per ASHRAE 170 recommendation of keeping occupied ventilation airflow rates between 4 to $12 \mathrm{ACH}$. With regards to the central plant, the boiler was assigned a 90\% efficiency and the chiller followed the ASHRAE recommended coefficient of performance (COP), unless the final model included purchased heating or cooling.

The peak design and all year simulation weather data was standardized between the early stage and final model. Prior to running the annual energy simulation, the room loads were run to calculate the peak load of each zone and 
the system loads were run to automatically size the equipment based on peak load.

\section{Results}

Once all modelling was completed and results produced, the percent change or deviation between final and early stage model were calculated. This was done via equation 1 below. The resulting percentages form the data set for this study.

$$
\text { Box Model Result - Final Model Results }
$$$$
\text { Final Model Results }
$$

\section{EUI deviations}

Table 3 provides a summary of the accuracy by looking at the percent change of the Energy Use Intensity (EUI).

Table 3: EUI deviations.

\begin{tabular}{|c|c|}
\hline Project ID & Percent Change, EUI \\
\hline Lab_5A_01 & $-33 \%$ \\
\hline Lab_5A_02 & $-36 \%$ \\
\hline Lab_5A_03 & $-32 \%$ \\
\hline Assembly_5A_01 & $-30 \%$ \\
\hline Dining_5A_01 & $-48 \%$ \\
\hline Office_3A_01 & $-12 \%$ \\
\hline Office_3A_02 & $-25 \%$ \\
\hline Office_3C_01 & $43 \%$ \\
\hline Office_3C_02 & $-18 \%$ \\
\hline Gym_3C_01 & $32 \%$ \\
\hline Education_3C_01 & $-39 \%$ \\
\hline
\end{tabular}

The box plots in Figure 3 show the full data set and the data with outliers are removed or cleaned. It is noted that the two outliers in the percent change EUI data were both positive values, while the remaining are negative. In addition, both are projects in climate zone 3C. Removing the two data points has impacted the average and third quartile significantly. The median deviation is essentially unchanged by removing the outliers and remains approximately at $-30 \%$. Interestingly, in a previous comparison of final design to calibrated models a similar deviation of $-31 \%$ to $-36 \%$ was found (Samuelson, Ghorayshi and Reinhart, 2015). Tying the two studies together, this suggests that early stage energy models could be at an over $60 \%$ underestimation of measured building energy use.

Table 4: Occupancy deviations.

\begin{tabular}{|c|c|}
\hline Project ID & Percent Change, Occupancy \\
\hline Lab_5A_01 & $-44 \%$ \\
\hline Lab_5A_02 & $-40 \%$ \\
\hline Lab_5A_03 & $1 \%$ \\
\hline Assembly_5A_01 & $-10 \%$ \\
\hline
\end{tabular}
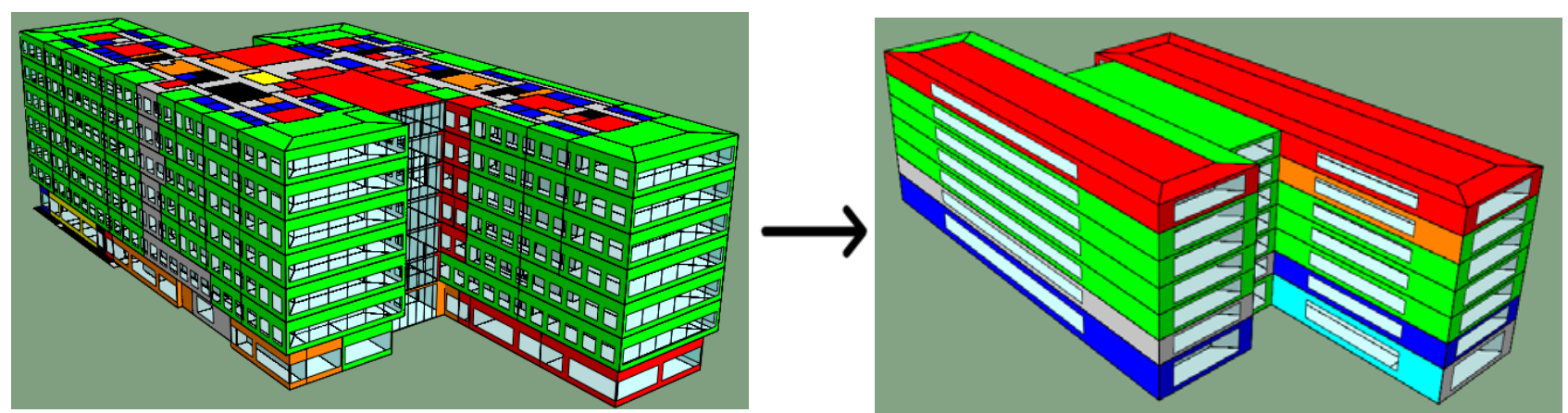

Figure 2: Visual example of a final model transformed into an early stage box model.

\begin{tabular}{|c|c|}
\hline Dining_5A_01 & $6 \%$ \\
\hline Office_3A_01 & $-39 \%$ \\
\hline Office_3A_02 & $-47 \%$ \\
\hline Office_3C_01 & $4 \%$ \\
\hline Office_3C_02 & $13 \%$ \\
\hline Gym_3C_01 & $13 \%$ \\
\hline Education_3C_01 & $-58 \%$ \\
\hline Average & $-21 \%$ \\
\hline Median & $-13 \%$ \\
\hline 1st Quartile & $-44 \%$ \\
\hline 3rd Quartile & $4 \%$ \\
\hline
\end{tabular}

\section{Occupancy deviations}

Occupancy is a large driver of several aspects of an energy model. As such the difference in occupancy between the final and early stage model was also studied. Table 4 provides the deviations of occupancy in the models along with the statistics. The median of this deviation is $-13 \%$ suggesting that final designs include more occupants than ASHRAE standards currently account for.

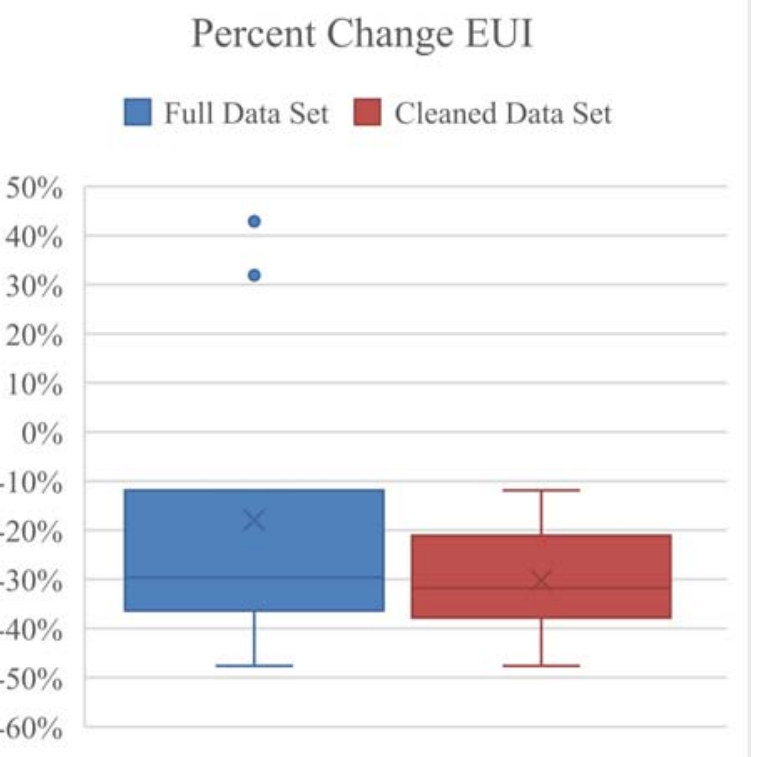

Figure 3: Percent change EUI box plots.

Table 5: Percent change EUI results.

\begin{tabular}{|c|c|c|}
\hline & Full Data Set & Cleaned Data Set \\
\hline Average & $-18 \%$ & $-30 \%$ \\
\hline Median & $-30 \%$ & $-32 \%$ \\
\hline 1st Quartile & $-36 \%$ & $-39 \%$ \\
\hline 3rd Quartile & $12 \%$ & $-21 \%$ \\
\hline
\end{tabular}




\section{End Use Deviations}

Delving deeper into the resulting data set, Figure 5 and Table 7 represent the percent change for each energy end use. This data provides a clearer picture of where deviation is occurring. The end uses with the largest median inaccuracies are Exterior Lighting at $-87 \%$, Fans Interior at $-63 \%$ and Elevators at $-60 \%$. The most predictable end uses are Space Cooling and Heat Rejection, both with approximately $40 \%$ between the first and third quartiles.

Three end uses have outliers in the data set: Space Cooling, Heat Rejection, and Service Water Heating. Figure 4 and Table 6 presents the cleaned data with the outliers removed.

The largest individual errors occurred in Space Heating and Service Water Heating at $164 \%$ and $252 \%$ percent error respectively. There are six instances of greater than $100 \%$ error spread across the data set. The most accurate end use is Plug Load with an average percent error of $2 \%$ and median of $3 \%$.

\section{End Use Percent Change Box Plots Cleaned}

Space Cooling $\square$ Heat Rejection SHW

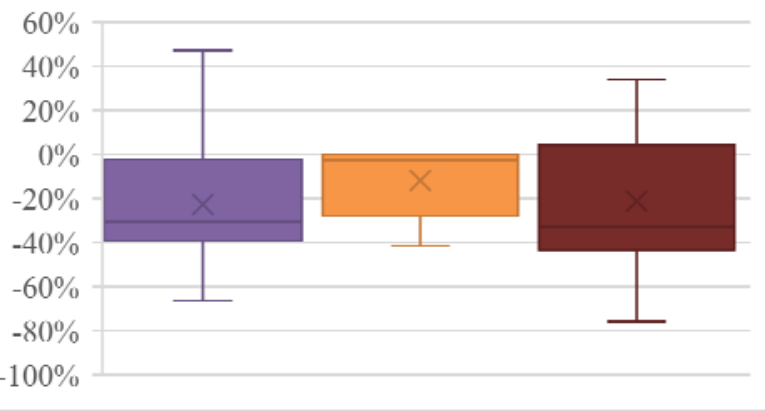

Figure 4: Space cooling, heat rejection \& SHW box plot. Table 6: Summary of Results.

\begin{tabular}{|c|c|c|c|}
\hline Average & $-25 \%$ & $-22 \%$ & $-24 \%$ \\
\hline Median & $-32 \%$ & $-24 \%$ & $-35 \%$ \\
\hline 1st Quartile & $-43 \%$ & $-39 \%$ & $-44 \%$ \\
\hline 3rd Quartile & $-14 \%$ & $-5 \%$ & $5 \%$ \\
\hline
\end{tabular}

\section{End Use Percent Change Box Plots}

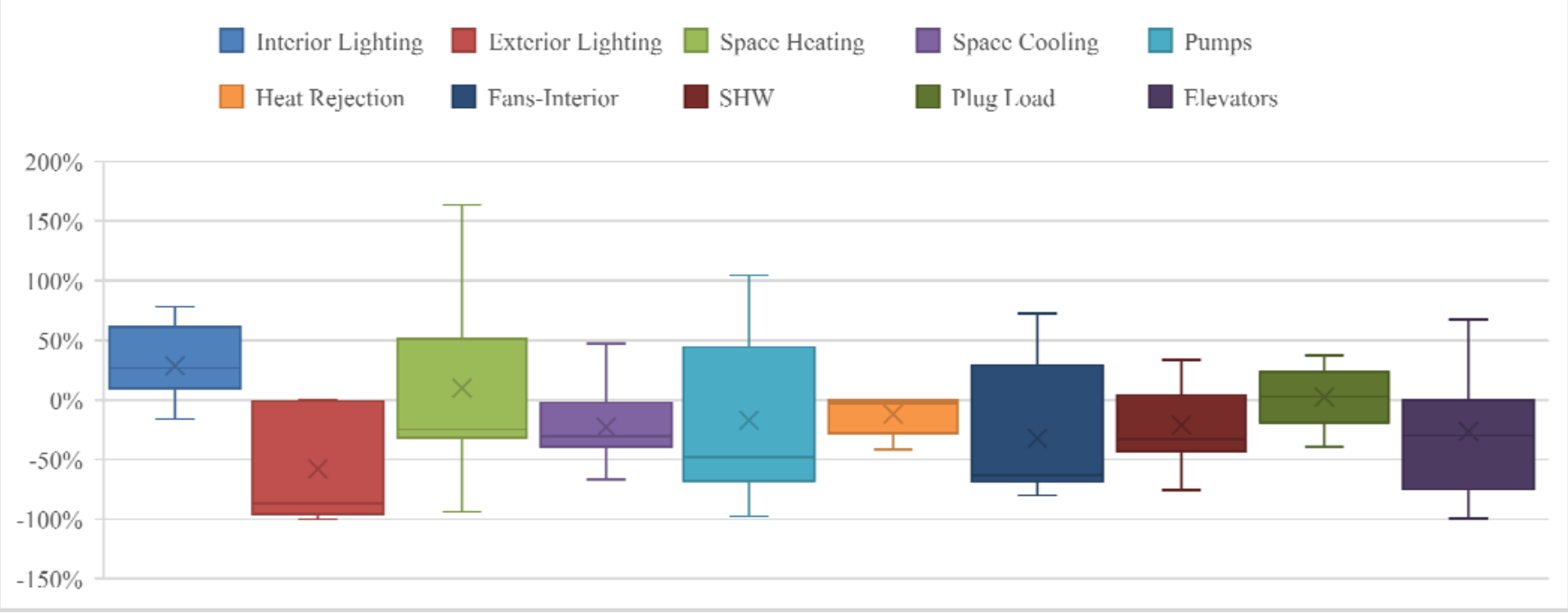

Figure 5: End use box plots.

Table 7: End use result table.

\begin{tabular}{|c|c|c|c|c|c|c|c|c|c|c|}
\hline & $\begin{array}{c}\text { Interior } \\
\text { Lighting }\end{array}$ & $\begin{array}{c}\text { Exterior } \\
\text { Lighting }\end{array}$ & $\begin{array}{c}\text { Space } \\
\text { Heating }\end{array}$ & $\begin{array}{c}\text { Space } \\
\text { Cooling }\end{array}$ & Pumps & $\begin{array}{c}\text { Heat } \\
\text { Rejection }\end{array}$ & $\begin{array}{c}\text { Fans } \\
\text { Interior }\end{array}$ & SHW & $\begin{array}{c}\text { Plug } \\
\text { Load }\end{array}$ & Elevators \\
\hline Average & $29 \%$ & $-58 \%$ & $10 \%$ & $-14 \%$ & $-21 \%$ & $-21 \%$ & $-32 \%$ & $25 \%$ & $2 \%$ & $-33 \%$ \\
\hline Median & $27 \%$ & $-87 \%$ & $-25 \%$ & $-31 \%$ & $-49 \%$ & $-24 \%$ & $-63 \%$ & $-16 \%$ & $9 \%$ & $-60 \%$ \\
\hline $\begin{array}{c}\text { 1st } \\
\text { Quartile }\end{array}$ & $10 \%$ & $-96 \%$ & $-32 \%$ & $-39 \%$ & $-82 \%$ & $-41 \%$ & $-69 \%$ & $-43 \%$ & $-19 \%$ & $-82 \%$ \\
\hline $\begin{array}{c}\text { 3rd } \\
\text { Quartile }\end{array}$ & $61 \%$ & $-1 \%$ & $52 \%$ & $10 \%$ & $66 \%$ & $-3 \%$ & $29 \%$ & $74 \%$ & $23 \%$ & $31 \%$ \\
\hline
\end{tabular}




\section{Discussion}

The 11 models were simulated and divided up per end use as highlighted in the results section. With the data collected from the LEED certified projects, the median EUI for an early stage model was 30\% lower than the final LEED model. This suggests a need for caution when the values are presented at early stages to guide expectations. Providing a range based on the results in Table 5 instead of a single value will help in representing where the project will be at the final design.

The largest drivers of the total EUI are space heating, space cooling, plug load and interior lighting. Noting the ranges of these end use results is also helpful in understanding what is likely to change between the early stage model and the final LEED models. For example, space heating and space cooling are both lower in the early stage models by a similar percentage to the total EUI as would be expected given they are such a large percentage of the total energy use.

One concern with the lower EUI of early stage models is how this may impact Life Cycle Cost Analysis (LCCA) of ECM options. For example, an option for a more efficient chilled water system run on an early stage model may suggest a lower savings and longer payback than if the same ECM was run on the detailed, more accurate final model. Understanding the variability of early stage models when preforming LCCA is important so that the results can be understood fairly. Using the results of this study, safety factors on the LCCA could be applied in order to most accurately determine savings via the early stage models. As with many aspects of energy modelling it is important for modelers to use experience and reasoning to determine when exact results may be misleading.

\section{Conclusion}

While these statistical findings provide insight into the deviations that would be seen from early stage design to final design, it is important to note that they must be used as representative correlations rather than absolute figures. The below section includes a detailed conclusion on the link between the modelling methodology employed and the deviations seen.

\section{Zoning methodology}

Zoning of the building volume into thermal blocks is an important step for all energy modelling. The zoning used in a final LEED model reflects closely the as-designed spaces of the building, including details such as shafts, voids, restrooms, and stairs. The early stage model framework utilizes zoning of the thermal blocks as laid out by ASHRAE 90.1 Appendix G, 4.5m perimeter blocks and larger internal core block (ASHRAE, 2016). The impact of zoning into these large thermal blocks has two impacts on the model performance. First, the dynamic solar gains are concentrated into only a few blocks and not dispersed over varied spaces with varied internal schedules of equipment and occupancy. Second, thermal blocks with no or minimal internal gains are replaced by more typical spaces that do include these gains. The small positive deviation seen for the plug loads can be explain in part by the second impact of the thermal zoning. First, the large thermal blocks have similar areas to if the blocks are broken up into the detailed final design block, thus keeping the deviation low. The deviation is positive due to the omission of thermal blocks with no internal gains such as voids. Replacing these voids with thermal blocks that include plug load explains the positive result of $9 \%$ median deviation for plug loads.

Grouping the solar gains and external losses into a limited number of thermal zone per ASHRAE 90.1 Appendix G limits spaces that will see multiple external gain peaks. For example, thermal blocks with East and South exposure are not created per the ASHRAE procedure.

\section{Simplified HVAC systems}

The early stage modelling framework generates a simplified HVAC system for the project based on the final design and several ASHRAE or other standard assumptions. This simplified HVAC system has several important differences compared to the final LEED model systems. First, the number of individual air-side systems is minimizing, this reduces the number of fans, heating coils, coiling coils, controllers, energy recovery devices and dampers. These larger, but fewer air-side systems offer less control over the spaces of the model. The scheduling of setpoints is also more generalized, leaving out any final LEED model configuration that may be required. Second, the water-side equipment efficiencies are simplified to assumptions that would be reasonable/possible at early stages. This further deviate from simplified HVAC system for its final LEED model pair.

Both pumps and fans are modelled using ASHRAE guidance, the results for both show that this underestimated the final model energy use. This may suggest that final designs are varying from the ASHRAE guidance and using more energy for pumps and fans. It is also partially related to the reduce usage of both cooling and heating, via the reduced airflow and water flow. Finally, it should be noted that pressure drop calculations are not done for early stage models and therefore the additional pressure drops of the final models are not accounted for.

Several detailed control strategies are omitted in the early stage models as they would typically not be accounted for in early design. Daylighting and occupancy controls are not included in the early stage models, this leads to the higher interior lighting use seen in the results. Exterior lighting is lower by a significant portion, a median of $86 \%$ suggesting final design incorporate more external lighting features than assumed in ASHRAE 90.1.

\section{Frame Work Modifications and Future Investigations}

An integral goal of this research was to investigate ways in which the framework developed for early stage energy modelling could be enhanced and improved upon. Drawing from the conclusions covered in this section, a number of observations can be made on the methods utilized. To start with, it was noted that the occupancy 
figures utilized in early stage models that reference ASHRAE 90.1 templates, have consistently been lower than the final actual occupancy numbers obtained from the client. Occupancy numbers affect ventilation rates and consequently heating and cooling figures. Hence, a modification to the framework could include a safety margin of $20 \%$ that increases occupancy numbers from ASHRAE figures at the beginning of design. Another refinement in modelling methodology could be made around glazing allocation. Early stage models, typically allocate a fixed percentage that is distributed evenly across all façade orientations. In various cases, it was found that design models had more glazing on Sothern or Northern orientations which would heavily impact both energy usage and peak loads throughout the year. Hence it is encouraged that project teams develop an appropriate strategy that aims to closely resemble design and glazing allocation. Finally, another modification could be made around the methodology of perimeter zoning. For this case study, we utilized the ASHRAE 90.1 guidance of $4.5 \mathrm{~m}$ perimeter zones (when internal partitioning is not determined yet). We believe that in some cases this could closely resemble design. Specifically, in open plan offices, where large areas are not partitioned off. However, we feel that this is one of the main causes behind the major discrepancies between the early models constructed and the final design. The reason being that the system configuration and ventilation approaches differ significantly when ventilating one large spaces, versus many small spaces.

Future investigations of this research will focus on several topics. The data set will be expanded to include a wider distribution of building types and climate zones. We believe that more granular insight can be gained in forming cross-climate and typology investigations on this modelling strategy. Specific studies will be carried out to further understand lab and office buildings as these are two building types with a large data set to draw from. In addition to this, different zoning methodologies will be investigated for large buildings. We will look to identify ways in which thermal zones could be sub-divided under the ASHRAE building Area method and test the sensitivities and impact of different approaches. Finally, when the framework has been tested out sufficiently, we would look to automate different aspects of it, specifically surrounding zoning the geometry and standardizing its usage firm-wide.

\section{Acknowledgement}

We would like to acknowledge the contribution of the New York, Los Angeles and San Francisco Arup Offices in sharing their LEED certified projects.

\section{References}

ANSI/ASHRAE/IESNA 90.1-2007 Energy Standard for Buildings Except Low-Rise Residential Buildings
ANSI/ASHRAE 62.1-2016 Ventilation for Acceptable Indoor Air Quality

ANSI/ASHRAE 55-2013 Thermal Environmental Conditions for Human Occupancy

ANSI/ASHRAE/ASHE 170-2017 Ventilation for Health Care Facilities

Ahmad, Mushtaq and Culp, Charles. (2006). Uncalibrated Building Energy Simulation Modeling Results. HVAC\&R Research. $12.1141-1155$. 10.1080/10789669.2006.10391455.

Berkeley, Pamela \& Haves, Philip \& Kolderup, Erik. (2014). Impact of modeler decisions on simulation results. 2014 ASHRAE/IBPSA-USA Building Simulation Conference. 203-210.

Delgarm, N., Sajadi, B., Azarbad, K. and Delgarm, S. (2018). Sensitivity analysis of building energy performance: A simulation-based approach using OFAT and variance-based sensitivity analysis methods. Journal of Building Engineering,15, 181-193.

De Wilde, P., Augenbroe, G., \& Van Der Voorden, M. (1999, September). Invocation of building simulation tools in building design practice. In Proceedings of IBPSA '99 Buildings Simulation Conference (pp. 1211-1218).

Dogan, T. and Reinhart, C. (2017). Shoeboxer: An algorithm for abstracted rapid multi-zone urban building energy model generation and simulation. Energy and Buildings, 140, 140153. doi:10.1016/j.enbuild.2017.01.030

IES (Integrated Environmental Solutions) VE, version 2017

Košir, M., Gostiša, T. and Kristl, Ž. (2018). Influence of architectural building envelope characteristics on energy performance in Central European climatic conditions. Journal of Building Engineering,15, 278-288. doi:10.1016/j.jobe.2017.11.023

Nikolaidou Elli \& Christina Hopfe. Robust Building Scheme Design Optimization for Uncertain Performance Prediction. In Proceedings of Building Simulation 2017, 07-09 August, San Francisco: USA

Østergård, T., Jensen, R. L. and Maagaard, S. E. (2018). A comparison of six metamodeling techniques applied to building performance simulations. Applied Energy, 211, 89-103. doi:10.1016/j.apenergy.2017.10.102

Pratt, K. B., Jones, N. L., Schumann, L., Bosworth, D. E., \& Heumann, A. D. (2012). Automated translation of architectural models for energy simulation. In Proceedings of the 2012 Symposium on Simulation for Architecture and Urban Design (p. 6). Society for Computer Simulation International.

Samuelson, H. W., Ghorayshi, A. and Reinhart, C. F. (2015). Analysis of a simplified calibration 
procedure for 18 design-phase building energy models. Journal of Building Performance Simulation, 9(1), 17-29. doi:10.1080/19401493.2014.988752

Theodosiou T., Performance Simulation Integrated in Parametric 3D Modeling as a Method for Early Stage Design Optimization-A Review. (2017). Energies, 10(5), 637. doi:10.3390/en10050637

W. Tian, J. Song, Z. Li \& P. de Wilde, Bootstrap techniques for sensitivity analysis and model selection in building thermal performance analysis, Appl. Energy 135 (2014) 320-328.

Zhou, H., Lee, S., \& Ying, H. (2018). VPL-Based Code Translation for Automated Compliance Checking of Building Envelope Energy Efficiency. Construction Research Congress 2018. doi:10.1061/9780784481301.001

Zhu, D., Hong, T., Yan, D., \& Wang, C. (2013). A detailed loads comparison of three building energy modeling programs: EnergyPlus, DeST and DOE-2.1E. Building Simulation, 6(3), 323335. doi:10.1007/s12273-013-0126-7 